\title{
Clinicopathologic Analysis of Lateral Margin Measured by Whole-Mount Section in T3 Rectal Cancer
}

\author{
Soomin $\mathrm{Nam}^{1}$, Youngki Hong ${ }^{1}$, Yoon Jung $\mathrm{Choi}^{2}$, Jung Gu Kang ${ }^{3}$ \\ ${ }^{1}$ Department of Surgery, National Health Insurance Service Ilsan Hospital, Goyang; ${ }^{2}$ Department of Pathology, National Health Insurance \\ Service Ilsan Hospital, Goyang; ${ }^{3}$ Department of Surgery, CHA University, Ilsan Cha Hospital, Goyang, Korea
}

Purpose: Total mesorectal excision is a standard technique for rectal cancer. The whole-mount section can encompass the entire specimen, so it is a more appropriate for measuring circumferential margin than conventional section. We analyzed the clinical characteristics and prognosis based on lateral margins (LMs) measured by whole-mount sections.

Methods: Medical records of patients who were operated on for T3 rectal cancer from 2005 to 2015 were reviewed retrospectively. A total of 154 patients were included. The slides of the whole-mount sections were re-reviewed by a single pathologist.

Results: We divided the groups according to the length of the LM ( $1 \mathrm{~mm}, 1.5 \mathrm{~mm}$, and $2 \mathrm{~mm})$. There was significantly frequent lymphovascular invasion and $\mathrm{N}$ state was higher when LM was short in all groups. There were more micrometastasis in group $\mathrm{LM} \leq 1 \mathrm{~mm}(53.3 \% \leq 1 \mathrm{~mm}$ vs. $26.6 \%>1 \mathrm{~mm}, \mathrm{P}=0.039)$, but not in other groups. When looking at local recurrence alone, there was no significant difference between groups, but the 5-year local recurrence-free survival was significantly worse when $\mathrm{LM} \leq 2 \mathrm{~mm}(\mathrm{P}=0.050)$. In each analysis based on $1 \mathrm{~mm}$ and $1.5 \mathrm{~mm}$, overall survival was worse when LM was short. In all groups, disease-specific survival was worse when LM was short.

Conclusion: As previously known, securing a margin less than $1 \mathrm{~mm}$ negatively affects the prognosis. When LM was divided by $1.5 \mathrm{~mm}$, there was a significant difference in overall survival. There was a significant difference in disease-specific survival when divided by $2 \mathrm{~mm}$ in T3 rectal cancer. However, further studies with more patients are necessary to secure the result.

Keywords: Rectal neoplasms; Whole-mount section; Prognosis; Lateral margin; Neoplasm micrometastasis

\section{INTRODUCTION}

Local recurrence after radical resection of rectal cancer has a significant effect on survival. Inadequate resection margin is one

Received: October 28, 2019 - Accepted: January 19, 2020

Correspondence to: Jung Gu Kang, M.D.

Department of Surgery, CHA University, Ilsan Cha Hospital, 1205 Jungang-ro, Ilsandong-gu, Goyang 10414, Korea

Tel: +82-31-782-8301, Fax: +82-31-782-83602, E-mail: kangski@chamc.co.kr ORCID: https://orcid.org/0000-0003-1282-5889

Co-Correspondence to: Yoon Jung Choi, M.D.

Department of Pathology, National Health Insurance Service Ilsan Hospital, 100 Ilsan-ro, Ilsandong-gu, Goyang 10444, Korea

Tel: +82-31-900-0256, Fax: +82-31-900-0019, E-mail: chris316@nhimc.or.kr ORCID: https://orcid.org/0000-0002-5701-8864

\section{(c) 2020 The Korean Society of Coloproctology}

This is an open-access article distributed under the terms of the Creative Commons Attribution NonCommercial License (https://creativecommons.org/licenses/by-nc/4.0) which permits unrestricted noncommercial use, distribution, and reproduction in any medium, provided the original work is properly cited. cause of local recurrence. Quirke et al. [1] reported that incomplete circumferential excision is a major risk factor for local recurrence of rectal cancer. Heald et al. proposed the concept of total mesorectal excision (TME) to reduce local recurrence of rectal cancer, and TME is now a standard technique for rectal cancer surgery $[2,3]$. Since the introduction of TME, the local recurrence rate has decreased to $3 \%-11 \%$ from $30 \%$ before TME [4].

In the field of pathologic examination, several methods have been studied to measure accurate lateral margins (LMs) and discover micrometastases, which are the risk factors for rectal cancer recurrence. Quirke et al. [1] suggested a whole-mount section for accurate measurement of the circumferential margin. This technique is still used as a standard procedure. Unlike the present general method of a conventional section, a whole-mount section can encompass all morphologic features of a surgical specimen, including the main lesion and mesorectum [5]. Because there is no distortion of the mesorectum during fixation with a wholemount section, precise measurement of the circumferential mar- 
gin is possible.

\section{METHODS}

Patients who had radical surgery for rectal cancer between January 2005 and December 2015 in the National Health Insurance Service Ilsan Hospital in Korea were included. Among these patients, 297 patients whose surgical specimen was diagnosed by a whole-mount section were included. Patients with synchronous or metachronous cancer were excluded, as were patients who underwent neoadjuvant chemoradiotherapy. We included patients with perirectal tissue invasion (T3), which is meaningful for measuring the LM in the mesorectum. Finally, 154 patients were included in this study. Their medical records were analyzed retrospectively. We collected their basic characteristics, including age and sex, laboratory results, and radiologic results.

Whole-mount sections were prepared using the following method. The postoperative specimen was delivered to the Department of Pathology without opening the rectum. This was fixed into $10 \%$ formalin for $24-48$ hours. The specimen was cut in a direction perpendicular to the long axis at 5-mm intervals. After additional fixation with $10 \%$ formalin, the slide including the whole-mount section was prepared. For this study, we reinvestigated tumor differentiation, depth of invasion, lymphovascular invasion (LVI), perineural invasion (PNI), and micrometastasis, which is defined as a nodule composed only of tumor cells without normal vascular or lymphatic structure in the mesorectum. When there was micrometastasis in the mesorectum, the shortest length from the micrometastasis or main tumor was measured as the LM.

We performed statistical analysis using IBM SPSS Statistics ver. 23.0 (IBM Co., Armonk, NY, USA). Quantitative outcomes are presented as mean and standard deviation, and categorical results as frequencies and percentages. Chi-square and Fisher exact tests were used to compare categorical variables. Independent t-tests were used to compare continuous variables. To identify risk factors, we used simple and multiple regression analyses. KaplanMeier analysis was used to identify the survival rate. A value of $\mathrm{P}<0.05$ was considered statistically significant. The study's protocol was reviewed and approved by the Institutional Review Board of the National Health Insurance Service Hospital (IRB No. 201604-026) and informed consent was waived.

\section{RESULTS}

Overall, 154 patients were retrospectively enrolled in this study. Patient demographics and clinical features are presented in Table 1. The mean age was $63.40 \pm 11.98$ years. There were 99 males (64.3\%) and 55 females (35.7\%). There were 116 patients (75.3\%) who underwent low anterior resection (LAR), 26 patients (16.9\%) who underwent LAR with intersphincteric resection, and $11 \mathrm{pa}-$ tients (7.1\%) who underwent abdominoperineal resection. Most
Table 1. Patient clinicopathologic characteristics

\begin{tabular}{lc}
\hline Features & Value \\
\hline Age $(\mathrm{yr})$ & $63.40 \pm 11.98$ \\
Sex & $99(64.3)$ \\
$\quad$ Male & $55(35.7)$ \\
Female & $12.13 \pm 34.53$ \\
CEA (ng/mL) ( $\mathrm{n}=144)$ & \\
Operation method & $116(75.3)$ \\
\hline LAR & $26(16.9)$ \\
LAR with intersphincteric resection & $11(7.1)$ \\
\hline Abdominoperineal resection & \\
Differentiation & $34(22.1)$ \\
Well differentiated & $114(74.0)$ \\
Moderately differentiated & $4(2.6)$ \\
Poorly differentiated & $2(1.3)$ \\
Mucinous & $5.72 \pm 1.54$ \\
Tumor size (cm) & $8.41 \pm 6.56$ \\
Lateral margin (mm) & $106(68.8)$ \\
Lymphovascular invasion $(\mathrm{n}=153)$ & $73(47.4)$ \\
Perineural invasion $(\mathrm{n}=152)$ & \\
\hline
\end{tabular}

Values are presented as mean \pm standard deviation or number (\%). CEA, carcinoembryonic antigen; LAR, low anterior resection.

of the patients had favorable differentiation of adenocarcinoma. The mean length of the LM was $8.41 \pm 6.56 \mathrm{~mm}$. (Table 1)

We divided the groups according to the length of the LM. Starting from the previously known significant $1 \mathrm{~mm} \mathrm{LM}$, the groups were divided into groups up to $2 \mathrm{~mm}$ at intervals of $0.5 \mathrm{~mm}$. There was no significant difference in clinical variables except for sex when the groups were divided into groups of LM by $1 \mathrm{~mm}$. More male patients were included in the group with less than 1 $\mathrm{mm}$ of LM $(\mathrm{P}=0.013)$. Some of the pathologic variables showed significant differences. There was significantly frequent LVI in the LM group $<1 \mathrm{~mm}(\mathrm{P}=0.039)$. There was no significant difference in PNI. More micrometastatic nodules were identified in the $\mathrm{LM}<1 \mathrm{~mm}$ group $(\mathrm{P}=0.039)$. There was no significant difference in TNM stage between the 2 groups $(\mathrm{P}=0.167)$, but a significant difference in $\mathrm{N}$ stage was seen. More lymph-node metastases were identified in the $\mathrm{LM}<1 \mathrm{~mm}$ group $(\mathrm{P}=0.027)$. (Table 2) There was no difference in most of the results when the groups were divided according to $1.5 \mathrm{~mm}$. There was significantly frequent LVI in the $\mathrm{LM}<1.5 \mathrm{~mm}$ group $(\mathrm{P}=0.024)$. The $\mathrm{LM}<1.5$ $\mathrm{mm}$ group showed significantly higher nodal stage $(\mathrm{P}=0.010)$ (Table 2). When we divided the groups by $2 \mathrm{~mm}$, there were no significant differences in clinical variables. Among pathological variables, there were more frequent LVI and PNI in the LM $<2$ $\mathrm{mm}(\mathrm{P}=0.029)$ group. More patients with lymph-node metastasis were included in the $\mathrm{LM}<2 \mathrm{~mm}$ group $(\mathrm{P}=0.027)$ (Table 2). 


\section{Coloproctolology}

Table 2. Comparison of clinicopathologic features followed by length of lateral margin by $1 \mathrm{~mm}, 1.5 \mathrm{~mm}$, and $2 \mathrm{~mm}$

\begin{tabular}{|c|c|c|c|c|c|c|c|c|c|}
\hline \multirow[b]{2}{*}{ Variable } & \multicolumn{9}{|c|}{ Lateral margin } \\
\hline & $\begin{array}{l}\leq 1 \mathrm{~mm} \\
(\mathrm{n}=15)\end{array}$ & $\begin{array}{l}>1 \mathrm{~mm} \\
(\mathrm{n}=139)\end{array}$ & P-value & $\begin{array}{c}\leq 1.5 \mathrm{~mm} \\
(\mathrm{n}=16)\end{array}$ & $\begin{array}{l}>1.5 \mathrm{~mm} \\
(\mathrm{n}=138)\end{array}$ & P-value & $\begin{array}{l}\leq 2 \mathrm{~mm} \\
(\mathrm{n}=25)\end{array}$ & $\begin{array}{c}>2 \mathrm{~mm} \\
(\mathrm{n}=129)\end{array}$ & P-value \\
\hline Age (yr) & $66.49 \pm 10.83$ & $63.06 \pm 12.09$ & 0.298 & $65.69 \pm 10.91$ & $63.13 \pm 12.11$ & 0.421 & $63.88 \pm 10.72$ & $63.30 \pm 12.25$ & 0.826 \\
\hline Male sex & $14(93.3)$ & $85(61.2)$ & 0.013 & $14(87.5)$ & $85(61.6)$ & 0.041 & $19(76.0)$ & $80(62.0)$ & 0.182 \\
\hline CEA (ng/mL) $(n=144)$ & $21.55 \pm 36.58$ & $11.20 \pm 34.33$ & 0.304 & $20.54 \pm 35.35$ & $11.23 \pm 34.46$ & 0.340 & $14.90 \pm 28.38$ & $11.61 \pm 35.66$ & 0.676 \\
\hline Preoperative clinical stage (TNM) & & & 0.182 & & & 0.186 & & & 0.205 \\
\hline । & $0(0)$ & $4(2.9)$ & & $0(0)$ & $4(2.9)$ & & $0(0)$ & $4(3.1)$ & \\
\hline$\|$ & $1(6.7)$ & $22(15.8)$ & & $1(6.3)$ & $22(15.9)$ & & $3(12.0)$ & $20(15.5)$ & \\
\hline III & $11(73.3)$ & $96(69.1)$ & & $12(75.0)$ & $95(68.8)$ & & $17(68.0)$ & $90(69.8)$ & \\
\hline IV & $3(20)$ & $17(12.2)$ & & $3(18.8)$ & $17(12.3)$ & & $5(20)$ & $15(11.6)$ & \\
\hline Operation method & & & 0.524 & & & 0.379 & & & 0.325 \\
\hline LAR & $10(71.4)$ & $106(76.3)$ & & $10(66.7)$ & $106(76.8)$ & & $16(66.7)$ & $100(77.5)$ & \\
\hline LAR with intersphincteric resection & $2(14.3)$ & $24(17.3)$ & & $3(20)$ & $23(16.7)$ & & $5(20.8)$ & $21(16.3)$ & \\
\hline Abdominoperineal resection & $2(14.3)$ & $9(6.5)$ & & $2(13.3)$ & $9(6.5)$ & & $2(12.5)$ & $8(6.2)$ & \\
\hline Differentiation & & & 0.505 & & & 0.531 & & & 0.809 \\
\hline Well differentiated & $4(26.7)$ & $30(21.6)$ & & $4(25.0)$ & $30(21.7)$ & & $6(24.0)$ & $28(21.7)$ & \\
\hline Moderately differentiated & $10(66.7)$ & $104(74.8)$ & & $11(68.8)$ & $103(74.6)$ & & $18(72.0)$ & $96(74.4)$ & \\
\hline Poorly differentiated & $1(6.7)$ & $3(2.2)$ & & $1(6.3)$ & $3(2.2)$ & & $1(4.0)$ & $3(2.3)$ & \\
\hline Mucinous & $0(0)$ & $2(1.4)$ & & $0(0)$ & $2(1.4)$ & & $0(0)$ & $2(1.6)$ & \\
\hline Tumor size (cm) & $6.15 \pm 1.76$ & $5.67 \pm 1.51$ & 0.259 & $6.15 \pm 1.70$ & $5.67 \pm 1.52$ & 0.238 & $5.89 \pm 1.69$ & $5.69 \pm 1.51$ & 0.551 \\
\hline Lymphovascular invasion $(n=153)$ & 14 (93.3) & $82(66.7)$ & 0.039 & $15(93.8)$ & $91(66.4)$ & 0.024 & $22(88.0)$ & $84(65.6)$ & 0.027 \\
\hline Perineural invasion $(n=152)$ & $9(60)$ & $64(46.7)$ & 0.328 & $9(56.3)$ & $64(47.1)$ & 0.486 & $17(68.0)$ & $56(44.1)$ & 0.029 \\
\hline Micrometastasis (+) & $8(53.3)$ & 37 (26.6) & 0.039 & $8(50)$ & $37(26.8)$ & 0.079 & $10(40)$ & $35(27.1)$ & 0.195 \\
\hline N stage & & & 0.027 & & & 0.010 & & & 0.047 \\
\hline NO & $2(13.3)$ & $62(44.6)$ & & $2(12.5)$ & $62(44.9)$ & & $6(24.0)$ & $58(45.0)$ & \\
\hline N1 & $4(26.7)$ & $37(26.6)$ & & $4(25.0)$ & $37(26.8)$ & & $6(24.0)$ & $35(27.1)$ & \\
\hline N2 & $9(60)$ & $40(28.8)$ & & $10(62.5)$ & 39 (28.3) & & $13(26.5)$ & $36(27.9)$ & \\
\hline TNM stage & & & 0.167 & & & 0.100 & & & 0.054 \\
\hline I & $0(0)$ & $1(0.7)$ & & $0(0)$ & $1(0.7)$ & & $0(0)$ & $1(0.8)$ & \\
\hline$\|$ & 2 (13.3) & $56(40.3)$ & & 2 (12.5) & 56 (40.6) & & $4(16.0)$ & $54(41.9)$ & \\
\hline III & $10(66.7)$ & $64(46.0)$ & & $11(68.8)$ & $63(45.7)$ & & $16(64.0)$ & $58(45.0)$ & \\
\hline IV & $3(20)$ & $18(12.9)$ & & $3(18.8)$ & $18(13.0)$ & & $5(20)$ & $16(12.4)$ & \\
\hline Adjuvant therapy, yes & $13(86.7)$ & $104(74.8)$ & 0.524 & 14 (87.5) & $103(74.6)$ & 0.360 & $22(88.0)$ & 95 (73.6) & 0.199 \\
\hline
\end{tabular}

Values are presented as mean \pm standard deviation or number (\%).

CEA, carcinoembryonic antigen; LAR, low anterior resection.

We compared the local recurrence according to LM length. There was no significant difference in local recurrence compared by LM of $1 \mathrm{~mm}, 1.5 \mathrm{~mm}$, or $2 \mathrm{~mm}$ (Table 3). Also, we analyzed 5 -year local recurrence-free survival by LM. There were no significant differences across all groups (Table 3).

We analyzed overall survival (OS) and disease-specific survival (DSS) according to each group (Fig. 1). There was a significant difference in $\mathrm{OS}$ in groups divided by $1 \mathrm{~mm}$ and $1.5 \mathrm{~mm}(\mathrm{P}<$
0.001 and $\mathrm{P}<0.001)$. However, there was no significant difference in OS in the LM $2 \mathrm{~mm}$ group $(\mathrm{P}=0.084)$ (Fig. 1A). In groups divided by $1 \mathrm{~mm}$, 3-year DSS, and 5-year DSS in the LM group < 1 $\mathrm{mm}$ were $63.80 \%$ and $23.90 \%$, and $86.10 \%, 72.70 \%$ in the LM group $>1 \mathrm{~mm}(\mathrm{P}<0.001)$. In the groups divided by $1.5 \mathrm{~mm}$ and 2 $\mathrm{mm}$, there were significant differences in DSS (Fig. 1B). There was no significant risk factor for OS and DSS including lymph node status and LM length. 
Table 3. Comparison of local recurrence according to lateral margin

\begin{tabular}{|c|c|c|c|c|c|c|c|c|c|}
\hline & & & & & Lateral margi & & & & \\
\hline & $\begin{array}{l}\leq 1 \mathrm{~mm} \\
(\mathrm{n}=15)\end{array}$ & $\begin{array}{c}>1 \mathrm{~mm} \\
(\mathrm{n}=139)\end{array}$ & P-value & $\begin{array}{c}\leq 1.5 \mathrm{~mm} \\
(\mathrm{n}=16)\end{array}$ & $\begin{array}{l}>1.5 \mathrm{~mm} \\
(\mathrm{n}=138)\end{array}$ & P-value & $\begin{array}{l}\leq 2 \mathrm{~mm} \\
(\mathrm{n}=25)\end{array}$ & $\begin{array}{r}>2 \mathrm{~mm} \\
(\mathrm{n}=129)\end{array}$ & P-value \\
\hline No recurrence & $14(93.3)$ & $131(94.2)$ & 1.000 & $15(93.8)$ & $130(94.2)$ & 1.000 & $22(88.0)$ & $123(95.3)$ & 0.163 \\
\hline Local recurrence & $1(6.7)$ & $8(5.8)$ & - & $1(6.3)$ & $8(5.8)$ & - & $3(12.0)$ & $6(4.7)$ & - \\
\hline 5-Year local recurrence-free survival & 83.3 & 92.9 & 0.533 & 85.7 & 92.8 & 0.676 & 82.5 & 93.6 & 0.050 \\
\hline
\end{tabular}

Values are presented as number (\%).
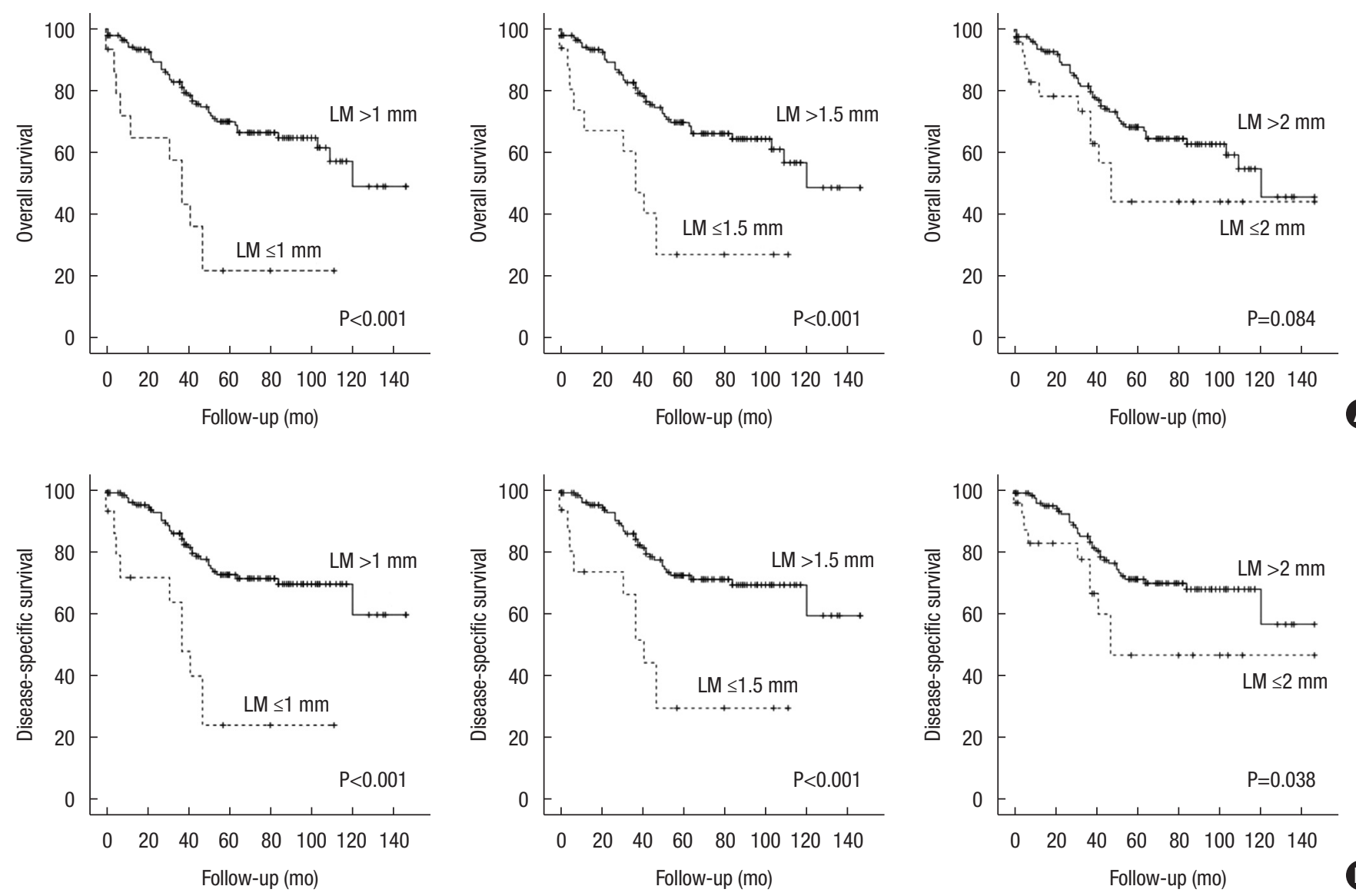

Fig. 1. Overall survival (OS) and disease-specific survival (DSS) by groups followed by length of lateral margin (LM).

\section{DISCUSSION}

Many studies have shown that sufficient circumferential margin in rectal cancer is important for prognosis such as recurrence and distant metastasis [6-8]. However, in most studies, pathologic diagnosis was achieved by dividing the lesion into several sections rather than a whole-mount section. This conventional method cannot identify accurate resection margins, because of the structural deformity during fixation, and the whole mesorectum may not be included in the slide. A whole-mount section can accurately measure a circumferential margin, because there is almost no distortion of the tissue while making the slide [1]. Because of the different processes for fixation and slices between the conventional and whole-mount methods, the length measured as $1 \mathrm{~mm}$ by these methods may be different in vivo. Therefore, in this study, we sought to discover significant lateral resection margins using whole-mount sections, because correct identification of these margins influences the survival rate of patients. The nodal stage called "N1c" was newly added to the 8th edition of the American Joint Committee on Cancer staging manual. N1c indicates that a tumor nodule has no lymph nodes or vascular tissue. These nodules can be found in the mesorectum. Therefore, it is 
important to investigate the mesorectum using a whole-mount section.

The rate of patients with positive LMs is reported to be from $1 \%$ to $28 \%$ [9]. Patients with a positive circumferential margin had more features of advanced disease. Clinically advanced $\mathrm{T}$ and $\mathrm{N}$ stage, tumor differentiation, LVI, and PNI are known to be significant predictors of a positive LM [10]. In our study, the patients with positive LMs showed more advanced cancer features (i.e., more LVI and a higher nodal stage). When we compared the clinicopathologic features according to an LM of $1.5 \mathrm{~mm}$ and $2 \mathrm{~mm}$, the results were similar.

As in previous studies, we found that having a lateral resection margin of less than $1 \mathrm{~mm}$ was associated with a negative effect on patient survival rate. It is well known that an LM less than $1 \mathrm{~mm}$ adversely affects local recurrence, distant metastasis, and survival [11]. Birbeck et al. [12] analyzed 608 patients with a whole-mount section and found that there was a significant difference in local recurrence rate among patients with a positive LM, an LM less than $1 \mathrm{~mm}$, and an LM more than $1 \mathrm{~mm}$. There was a significant difference in the hazard ratio for death and recurrence when the LM was less than $1 \mathrm{~mm}$ [13]. Even after neoadjuvant chemoradiotherapy in locally advanced rectal cancer, an LM of less than 1 $\mathrm{mm}$ was an independent risk factor for local recurrence $[14,15]$. AN LM of less than $2 \mathrm{~mm}$ showed more distant metastases [14]. There have been other studies which compared survival and recurrence according to an LM of more than $1 \mathrm{~mm}$. Most studies have been based on a $1 \mathrm{~mm}$ margin, because it is traditionally regarded as marginal positive. Nagtegaal et al. [8] reported that an LM of less than $2 \mathrm{~mm}$ showed significantly more local recurrence. Some studies found worse prognosis, including local recurrence, distant metastasis, and OS, with an LM of less than $2 \mathrm{~mm}$ [16-18]. Patients with an LM of less than $5 \mathrm{~mm}$ died more often than did patients with a margin more than $5 \mathrm{~mm}$ [19]. In this study, when the lateral resection margin was less than $1 \mathrm{~mm}$ or $1.5 \mathrm{~mm}$, there was a significant difference in OS. And there was a significant difference in DSS when the lateral resection margin was less than 1 $\mathrm{mm}, 1.5 \mathrm{~mm}$, or $2 \mathrm{~mm}$. When the LM was less than $2 \mathrm{~mm}$, there was a significant difference in local recurrence-free survival between groups. Because of the small number of patients, we could not analyze each interval by group in this study.

Many studies have mentioned the relationship between small LM and more local recurrence. We included only 154 patients in this study. There were only 9 patients $(5.84 \%)$ with local recurrence after radical operation. Our local recurrence rates are not significantly different from those in other studies. However, the small number of local recurrent patients is a limitation of this study. For this reason, it was difficult to provide reliable results for LM and local recurrence. There are limitations with respect to accepting the results of this study in general, because the number of patients is not sufficient. Further studies with more patients may yield better results.

The whole-mount section has the advantage that the whole rec- tal cancer specimen can be observed without distortion of its structure. Therefore, this method can provide a more extensive and precise pathologic result. However, because of the difficulties associated with this method, such as the time, cost, and special equipment required to produce whole-mount slides, it is not widely used in clinical practice. In this study, we analyzed clinicopathologic features compared among groups with LMs measured by whole-mount sections. Only T3 patients were included to focus more on the meaning of the whole-mount section in advanced rectal cancer. Previously, LM was discussed with only "1 mm." However, in this study, to extend the range to $1.5 \mathrm{~mm}$ and 2 $\mathrm{mm}$ was meaningful. The " $2 \mathrm{~mm}$ " LM also showed significant differences in prognosis. Therefore, it will be necessary to secure as much of the LM as possible in rectal cancer pathological specimens.

\section{CONFLICT OF INTEREST}

No potential conflict of interest relevant to this article was reported.

\section{REFERENCES}

1. Quirke P, Durdey P, Dixon MF, Williams NS. Local recurrence of rectal adenocarcinoma due to inadequate surgical resection. Histopathological study of lateral tumour spread and surgical excision. Lancet 1986;2:996-9.

2. Heald RJ, Husband EM, Ryall RD. The mesorectum in rectal cancer surgery--the clue to pelvic recurrence? Br J Surg 1982;69:6136.

3. Enker WE. Total mesorectal excision--the new golden standard of surgery for rectal cancer. Ann Med 1997;29:127-33.

4. Lee SH, Hernandez de Anda E, Finne CO, Madoff RD, GarciaAguilar J. The effect of circumferential tumor location in clinical outcomes of rectal cancer patients treated with total mesorectal excision. Dis Colon Rectum 2005;48:2249-57.

5. Ng IO, Luk IS, Yuen ST, Lau PW, Pritchett CJ, Ng M, et al. Surgical lateral clearance in resected rectal carcinomas. A multivariate analysis of clinicopathologic features. Cancer 1993;71:1972-6.

6. de Haas-Kock DF, Baeten CG, Jager JJ, Langendijk JA, Schouten LJ, Volovics A, et al. Prognostic significance of radial margins of clearance in rectal cancer. Br J Surg 1996;83:781-5.

7. Adam IJ, Mohamdee MO, Martin IG, Scott N, Finan PJ, Johnston $\mathrm{D}$, et al. Role of circumferential margin involvement in the local recurrence of rectal cancer. Lancet 1994;344:707-11.

8. Nagtegaal ID, Marijnen CA, Kranenbarg EK, van de Velde CJ, van Krieken JH; Pathology Review Committee, et al. Circumferential margin involvement is still an important predictor of local recurrence in rectal carcinoma: not one millimeter but two millimeters is the limit. Am J Surg Pathol 2002;26:350-7.

9. Nagtegaal ID, Quirke P. What is the role for the circumferential margin in the modern treatment of rectal cancer? J Clin Oncol 
2008;26:303-12.

10. Rickles AS, Dietz DW, Chang GJ, Wexner SD, Berho ME, Remzi $\mathrm{FH}$, et al. High rate of positive circumferential resection margins following rectal cancer surgery: a call to action. Ann Surg 2015; 262:891-8.

11. Lin HH, Lin JK, Lin CC, Lan YT, Wang HS, Yang SH, et al. Circumferential margin plays an independent impact on the outcome of rectal cancer patients receiving curative total mesorectal excision. Am J Surg 2013;206:771-7.

12. Birbeck KF, Macklin CP, Tiffin NJ, Parsons W, Dixon MF, Mapstone NP, et al. Rates of circumferential resection margin involvement vary between surgeons and predict outcomes in rectal cancer surgery. Ann Surg 2002;235:449-57.

13. Marks, Reid, Lewis, Jackson, Cook. What determines the outcome after total mesorectal excision for rectal carcinoma- 15 years experience of a specialist surgical unit. Colorectal Dis 2000;2:2706.

14. Trakarnsanga A, Gonen M, Shia J, Goodman KA, Nash GM, Temple LK, et al. What is the significance of the circumferential margin in locally advanced rectal cancer after neoadjuvant chemoradiotherapy? Ann Surg Oncol 2013;20:1179-84.
15. Marijnen CA, Nagtegaal ID, Kapiteijn E, Kranenbarg EK, Noordijk EM, van Krieken JH, et al. Radiotherapy does not compensate for positive resection margins in rectal cancer patients: report of a multicenter randomized trial. Int J Radiat Oncol Biol Phys 2003; 55:1311-20.

16. Luna-Pérez P, Bustos-Cholico E, Alvarado I, Maffuz A, Rodríguez-Ramírez S, Gutiérrez de la Barrera M, et al. Prognostic significance of circumferential margin involvement in rectal adenocarcinoma treated with preoperative chemoradiotherapy and low anterior resection. J Surg Oncol 2005;90:20-5.

17. Bernstein TE, Endreseth BH, Romundstad P, Wibe A; Norwegian Colorectal Cancer Group. Circumferential resection margin as a prognostic factor in rectal cancer. Br J Surg 2009;96:1348-57.

18. Bouzourene H, Bosman FT, Matter M, Coucke P. Predictive factors in locally advanced rectal cancer treated with preoperative hyperfractionated and accelerated radiotherapy. Hum Pathol 2003;34:541-8.

19. Kelly SB, Mills SJ, Bradburn DM, Ratcliffe AA, Borowski DW; Northern Region Colorectal Cancer Audit Group. Effect of the circumferential resection margin on survival following rectal cancer surgery. Br J Surg 2011;98:573-81. 